\title{
Comparison of InAs/GaAs Quantum Dot Infrared Photodetector and GaAs/(AlGa)As Superlattice Infrared Photodetector
}

Shih-Yen LIN, Yao-Jen TSAI and Si-Chen LEE*

Department of Electrical Engineering, National Taiwan University, Taipei, Taiwan, Republic of China

(Received June 25, 2001; accepted for publication August 31, 2001)

A 10-stacked InAs/GaAs quantum dot infrared photodetector (QDIP) is compared with a 20-period GaAs/(AlGa)As superlattice infrared photodetector (SLIP). The $2-10 \mu \mathrm{m}$ wide detection window and $187 \mathrm{~mA} / \mathrm{W}$ high peak responsivity of InAs/GaAs QDIP at $7 \mu \mathrm{m}$ at an applied voltage of $1.1 \mathrm{~V}$ are superior to the $7-10 \mu \mathrm{m}$ detection window and $140 \mathrm{~mA} / \mathrm{W}$ responsivity of $\mathrm{GaAs} /(\mathrm{AlGa}) \mathrm{As}$ SLIP at $9.4 \mu \mathrm{m}$ at an applied voltage of $1.3 \mathrm{~V}$. The photocurrent of SLIP is temperature-independent, whereas the photocurrent of QDIP increases with increasing temperature from 20 to $100 \mathrm{~K}$. The polarization-dependent response ratios of 0.22 and 0.39 are observed for SLIP and QDIP, respectively.

KEYWORDS: quantum dot, superlattice, infrared photodetector

Nano-structure infrared photodetectors for use in intersubband transitions have been widely investigated in recent years. ${ }^{1-11)}$ Among various kinds of infrared photodetectors, GaAs/(AlGa)As quantum well structures have been optimized as focal plane arrays for infrared image sensing. ${ }^{9,10}$ ) However, the polarization-dependent selection rule of the quantum well infrared photodetector (QWIP) and superlattice infrared photodetector (SLIP) has enabled the use of additional light coupling scheme being used under normal incident condition. ${ }^{3,4)}$ On the other hand, the quantum dot infrared photodetector (QDIP) has demonstrated normal incident absorption in several reports. ${ }^{6,8)}$ Hence, the possibility of replacement of QWIP or SLIP with QDIP has become an important issue regarding the applications of infrared detectors with semiconductor nano-structures. To investigate the different performances of the devices, 10-stacked InAs/GaAs QDIP and 20-period GaAs/(AlGa)As SLIP are discussed in this paper. At compatible responsivity, QDIP has a high transverse electric/transverse magnetic (TE/TM) response ratio and wide detection window compared with SLIP. The increase and invariance of photocurrent with increasing temperature are also observed for QDIP and SLIP, respectively.

The QDIP and SLIP are grown on a (100) semi-insulting GaAs substrate by VG $80 \mathrm{H}$ solid source molecular beam epitaxy at $510^{\circ} \mathrm{C}$ and $580^{\circ} \mathrm{C}$, respectively. The device structures are listed in Table I. Sandwiched between $0.5 \mu \mathrm{m}$ top and $1 \mu \mathrm{m}$ bottom GaAs contact layers doped with $\mathrm{Si}$ to $1 \times 10^{18} \mathrm{~cm}^{-3}$, the QDIP structure consists of 10 periods of 3 ML InAs QDs and $30 \mathrm{~nm}$ GaAs barriers, where each $3 \mathrm{ML}$ InAs quantum dot layer is grown in the Stranski-Krastanov $(\mathrm{S}-\mathrm{K})$ growth mode and uniformly doped to $1 \times 10^{18} \mathrm{~cm}^{-3}$ under arsenic shutter closed condition. The SLIP structure consists of 20 periods of $6 \mathrm{~nm} \mathrm{GaAs}$ wells and $4 \mathrm{~nm} \mathrm{Al}_{0.3} \mathrm{Ga}_{0.7} \mathrm{As}$ barriers, where the GaAs layer is doped to $1 \times 10^{18} \mathrm{~cm}^{-3}$ at the middle $3 \mathrm{~nm}$ layer with the initial and final $1.5 \mathrm{~nm}$ GaAs layers left undoped to prevent severe Si segregation. ${ }^{12)}$ To suppress the dark current of the SLIP device, two $50 \mathrm{~nm}$ $\mathrm{Al}_{0.3} \mathrm{Ga}_{0.7} \mathrm{As}$ blocking layers are grown at each side of the superlattice structure. After a two-step process, $100 \times 100 \mu \mathrm{m}^{2}$ devices are fabricated. The responsivities of the devices are measured under an edge-coupling scheme with advanced products department (APD) cryogenics and a Perkin-Elmer

*E-mail address: sclee@cc.ee.ntu.edu.tw
S2000 Fourier transform infrared (FTIR) spectroscopy. The absolute value of spectral responsivity is calibrated with a standard blackbody radiation source operated at $1080 \mathrm{~K}$. By carefully shielding the device from background infrared radiation, dark $I-V$ curves are measured with an HP4145A semiconductor parameter analyzer.

As shown in Fig. 1, the peak responsivity of SLIP at $20 \mathrm{~K}$ is $140 \mathrm{~mA} / \mathrm{W}$ at $9.4 \mu \mathrm{m}$ under an applied voltage of $1.3 \mathrm{~V}$ and for QDIP, $187 \mathrm{~mA} / \mathrm{W}$ at $7 \mu \mathrm{m}$ under an applied voltage of 1.1 V. The superior peak response of QDIP proves highquality molecular beam epitaxy (MBE)-prepared QD samples. Also observed is the higher spectral broadening $\Delta \lambda / \lambda_{\mathrm{P}}$ $50 \%$ of QDIP than that (32\%) of SLIP. The higher spectral broadening of QDIP is attributed to the size variation of quantum dots, ${ }^{13,14)}$ while only one miniband-to-miniband transition is responsible for the measured response of SLIP. To explain the performances of QDIP and SLIP, the band diagrams of the devices under thermal equilibrium are shown in Fig. 2. The energy levels of quantum dot and superlattice structures are calculated using a transfer matrix method, where the height of InAs QD, i.e., $6 \mathrm{~nm}$, is obtained through atomic force microscopy (AFM) measurement. The photoresponse of QDIP is thus attributed to the $E_{2, \mathrm{QD}}$-continuum transition with the corresponding wavelength of $6.36 \mu \mathrm{m}$ and

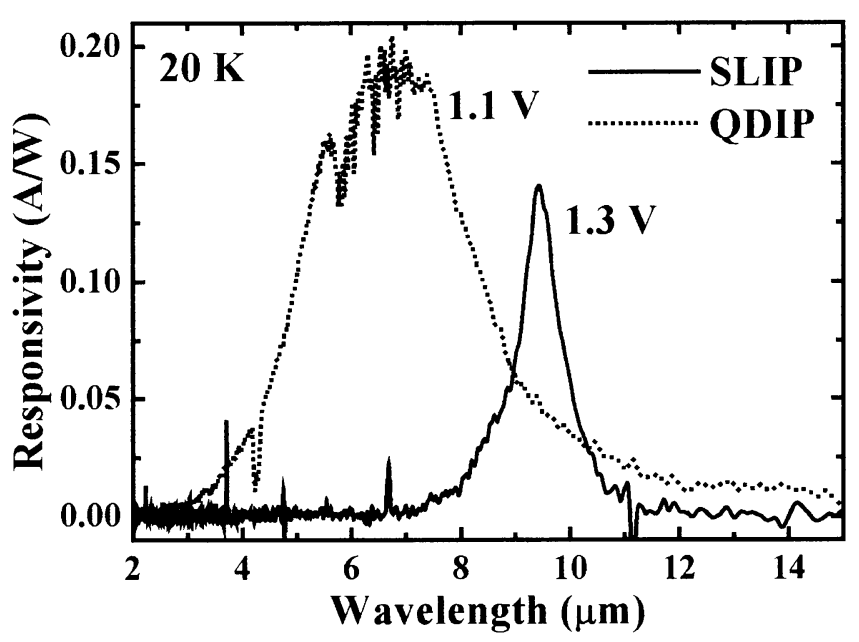

Fig. 1. Responsivities of SLIP and QDIP as a function of wavelength at $20 \mathrm{~K}$ under positive biases of 1.3 and $1.1 \mathrm{~V}$, respectively. 
Table I. Sample structures of SLIP and QDIP

\begin{tabular}{|c|c|c|c|}
\hline & SLIP & QDIP & \\
\hline \multirow{8}{*}{20 periods } & \multicolumn{2}{|c|}{$0.5 \mu \mathrm{m} \mathrm{GaAs} n=1 \times 10^{18} \mathrm{~cm}^{-3}$} & \multirow{8}{*}{10 periods } \\
\hline & $50 \mathrm{~nm} \mathrm{Al}_{0.3} \mathrm{Ga}_{0.7} \mathrm{As}$ undoped & - & \\
\hline & $6 \mathrm{~nm} \mathrm{GaAs} n=5 \times 10^{17} \mathrm{~cm}^{-3}$ & $30 \mathrm{~nm}$ GaAs undoped & \\
\hline & $4 \mathrm{~nm} \mathrm{Al}_{0.3} \mathrm{Ga}_{0.7} \mathrm{As}$ undoped & $3 \mathrm{ML}$ InAs QD $n=1 \times 10^{18} \mathrm{~cm}^{-3}$ & \\
\hline & $6 \mathrm{~nm} \mathrm{GaAs} n=5 \times 10^{17} \mathrm{~cm}^{-3}$ & $30 \mathrm{~nm} \mathrm{GaAs}$ undoped & \\
\hline & $50 \mathrm{~nm} \mathrm{Al}{ }_{0.3} \mathrm{Ga}_{0.7}$ As undoped & - & \\
\hline & $1 \mu \mathrm{m} \mathrm{GaA}$ & $1 \times 10^{18} \mathrm{~cm}^{-3}$ & \\
\hline & $450 \mu \mathrm{n}$ & Is Substrate & \\
\hline
\end{tabular}

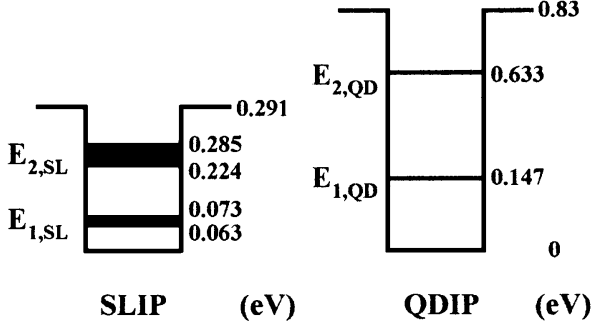

(a)

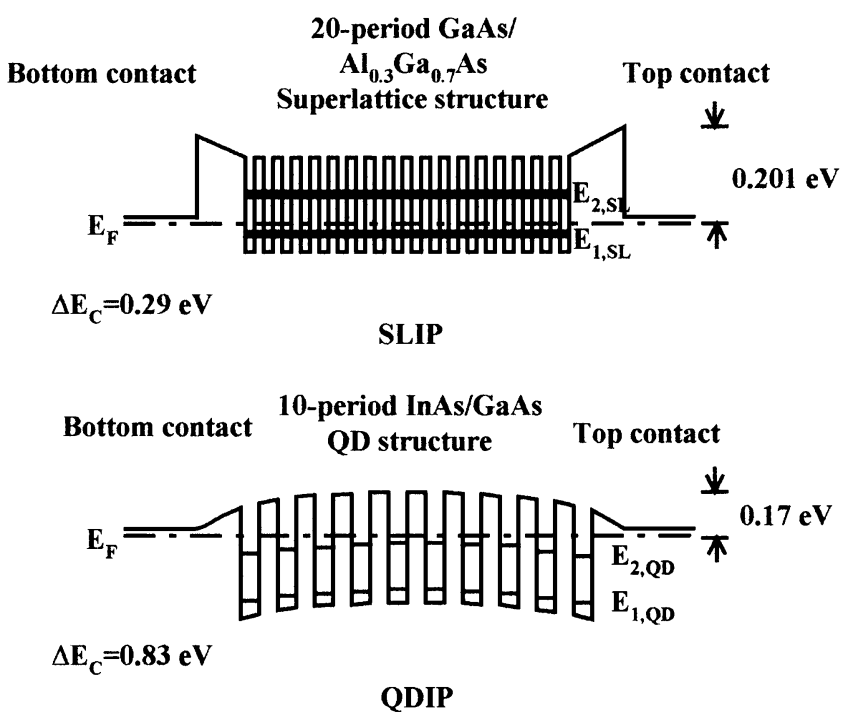

(b)

Fig. 2. (a) Calculated energy levels of SLIP and QDIP using a transfer matrix method. (b) Band diagrams of SLIP and QDIP where the Fermi levels are derived through curve fitting of temperature-dependent dark currents.

that of SLIP to the $E_{1, \mathrm{SL}}-E_{2, \mathrm{SL}}$ miniband transition. Also shown in Fig. 2 are the Fermi levels of the devices determined empirically through curve fitting of the temperaturedependent dark currents. ${ }^{13,15)}$

By integrating the spectral responses of SLIP and QDIP at 20 and $100 \mathrm{~K}$ over the wavelength, the relative photocurrents under different biases are shown in Fig. 3(a). The photocurrent of QDIP increases with increasing temperature while it remains unchanged for SLIP. The difference in these two devices lies in the different limitations on intersubband tran-

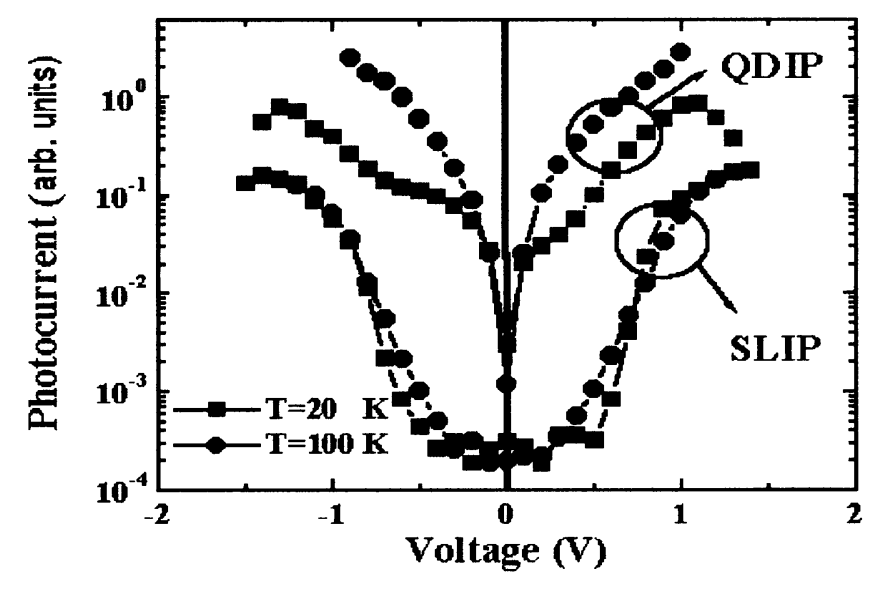

(a)

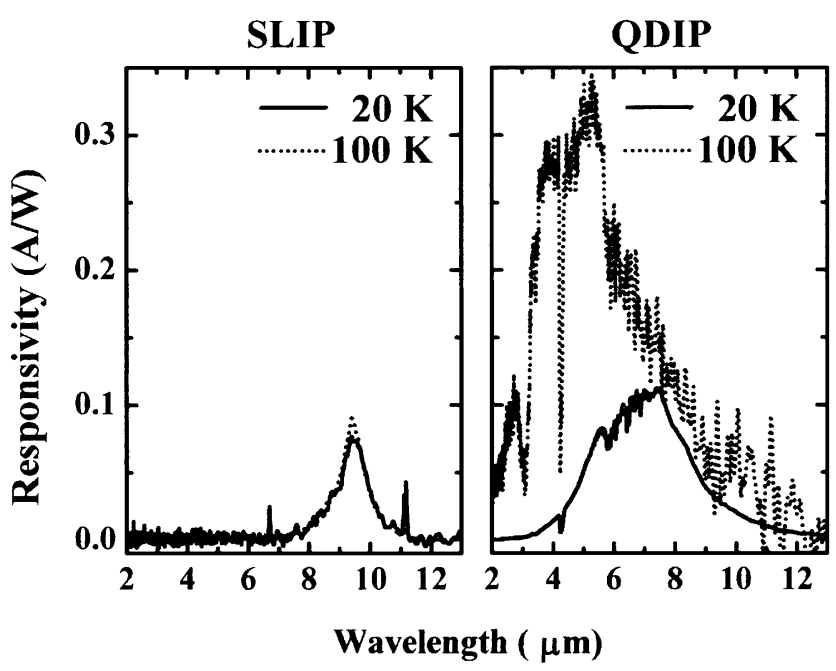

(b)

Fig. 3. (a) Relative photocurrents of SLIP and QDIP under different biases at 20 and $100 \mathrm{~K}$, respectively. (b) Spectral responses of SLIP and QDIP at 20 and $100 \mathrm{~K}$ at applied voltages of 1.1 and $0.8 \mathrm{~V}$, respectively.

sitions of SLIP and QDIP. As shown in Fig. 2, the Fermi level of the QD structure is $0.66 \mathrm{eV}$ above the conduction band edge which is higher than the $E_{2, \mathrm{QD}}$ state. With increasing temperature, $E_{2, \mathrm{QD}}$ states will be depopulated, then the $E_{1}-E_{2}$ and $E_{2}$-tunneling transitions occur. As shown in Fig. 


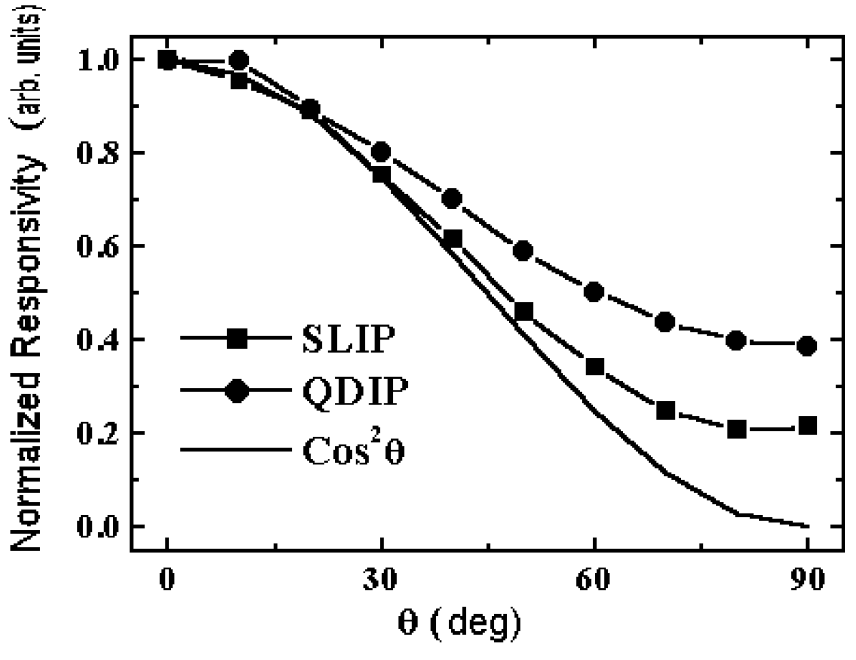

Fig. 4. Polarization dependence of SLIP and QDIP measured at $20 \mathrm{~K}$ where the degree $\theta$ represents the polarization angle between the $\mathrm{TM}\left(0^{\circ}\right)$ and TE $\left(90^{\circ}\right)$ modes.

3(b), the photocurrent at 2-6 $\mathrm{m}$ would, consequently, increase with increasing temperature. For the superlattice structure, the Fermi level is $16 \mathrm{meV}$ above the first miniband $E_{1, \mathrm{SL}}$ and $135 \mathrm{meV}$ below the second miniband $E_{2, \mathrm{SL}}$. With increasing temperature, although the empty states at $E_{1, \mathrm{SL}}$ miniband slightly increase, the optical absorption is still remaining the same since $E_{2, \mathrm{SL}}$ is almost empty. In the temperature range of our interest, $20-100 \mathrm{~K}$, the absorption efficiency should be constant so that photocurrent of SLIP remains unchanged with increasing temperature as shown in Fig. 3(b).

The normalized responsivities of SLIP and QDIP under different incident polarizations are shown in Fig. 4. According to the dipole transition theory, a $\cos ^{2} \theta$ term would appear in the expression of oscillation strength of the quantum well intersubband transition, where $\theta$ is the polarization angle of the incident light $\left(0^{\circ}\right.$ for the TM mode and $90^{\circ}$ for the TE mode). The TE/TM mode response ratios are 0.22 and 0.39 for SLIP and QDIP, respectively. The derivation of the TE mode response of unstrained SLIP from a zero theoretical value is attributed to scattering at the device edge such that non-TE mode radiation would cause intersubband absorption. ${ }^{16)}$ By the same alignment and measurement procedure, it is shown that the TE mode absorption of InAs/GaAs QDIP reaches $39 \%$ of the value of TM mode absorption.

In conclusion, InAs/GaAs QDIP is compared with
GaAs/(AlGa)As SLIP. Higher peak responsivity and spectral broadening are observed for QDIP. With increasing temperature from 20 to $100 \mathrm{~K}$, the photocurrent of SLIP remains constant whereas that of QDIP increases. In addition, the TE/TM mode response ratios are 0.22 and 0.39 for SLIP and QDIP, respectively. The nonzero TE mode response of SLIP is attributed to the device edge scattering of incident light. The higher TE/TM mode response ratio and the increase of photocurrent with increasing temperature have shown the advantages of QDIP for application to normal-incident absorption and high-temperature operation. According to the results, the $2-10 \mu \mathrm{m}$ wide detection window and $187 \mathrm{~mA} / \mathrm{W}$ high peak responsivity of InAs/GaAs QDIP at $7 \mu \mathrm{m}$ at an applied voltage of $1.1 \mathrm{~V}$ are superior to the $7-10 \mu \mathrm{m}$ detection window and $140 \mathrm{~mA} / \mathrm{W}$ responsivity of $\mathrm{GaAs} /(\mathrm{AlGa}) \mathrm{As}$ SLIP at $9.4 \mu \mathrm{m}$ at an applied voltage of $1.3 \mathrm{~V}$.

This work was partly supported by the National Science Council of the Republic of China under contract No. NSC 892215-E-002-057.

1) M. Z. Tidrow, X. Jiang, S. S. Li and K. Bacher: Appl. Phys. Lett. 74 (1999) 1335

2) S. D. Gunapala, S. V. Bandara, J. K. Liu, W. Hong, M. Sundaram, P. D. Maker, R. E. Muller, C. A. Shott and R. Carralejo: IEEE Trans. Electron Devices 45 (1998) 1890.

3) C. J. Chen, K. K. Choi, W. H. Chang and D. C. Tsui: Appl. Phys. Lett. 73 (1998) 1272.

4) Y. Fu, M. Willander, W. Lu and W. Xu: J. Appl. Phys. 84 (1998) 5750.

5) T. Mei, G. Karunasiri and S. J. Chua: Appl. Phys. Lett. 71 (1997) 2017.

6) J. Phillips, K. Kamath and P. Bhattacharya: Appl. Phys. Lett. 72 (1998) 2020.

7) D. Pan, E. Towe and S. Kennerly: Appl. Phys. Lett. 73 (1998) 1937.

8) S. Kim, H. Mohseni, M. Erdtmann, E. Michel, C. Jelen and M. Razeghi: Appl. Phys. Lett. 73 (1998) 963.

9) S. D. Gunapala, J. K. Liu, J. S. Park, M. Sundaram, C. A. Shott, T. Hoelter, T. L. Lin, S. T. Massie, P. D. Maker, R. E. Muller and G. Sarusi: IEEE Trans. Electron Devices 44 (1997) 51.

10) S. D. Gunapala, S. V. Bandara, J. K. Liu, W. Hong, M. Sundaram, P. D. Maker, R. E. Muller, C. A. Shott and R. Carralejo: IEEE Trans. Electron Devices 45 (1998) 1890.

11) S. F. Tang, S. Y. Lin and S. C. Lee: Appl. Phys. Lett. 78 (2001) 2428.

12) E. C. Larkins, H. Schneider, S. Ehret, J. Fleibner, B. Dischler, P. Koidl and J. D. Ralston: IEEE Trans. Electron Devices 41 (1994) 511.

13) S. Y. Lin, Y. R. Tsai and S. C. Lee: Appl. Phys. Lett. 78 (2001) 2784.

14) H. C. Liu, M. Gao, J. Mccaffrey, Z. R. Wasilewski and S. Fafard: Appl. Phys. Lett. 78 (2001) 79.

15) G. Sarusi, S. D. Gunapala, J. S. Park and B. F. Levine: J. Appl. Phys. Lett. 76 (1994) 6001.

16) H. C. Liu, M. Buchanan and Z. R. Wasilewski: Appl. Phys. Lett. 72 (1998) 1682. 